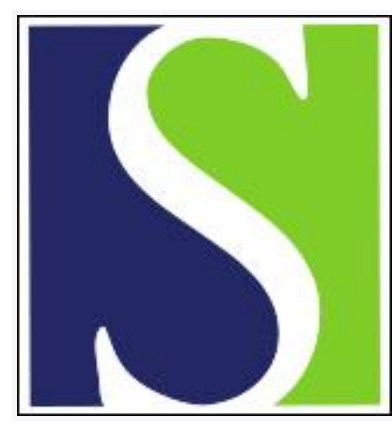

Scand J Work Environ Health 2004;30(5):337-338

https://doi.org/10.5271/sjweh.820

Issue date: Oct 2004

\title{
Lack of randomization in occupational epidemiology
}

by Kristensen $P$

Affiliation: National Institute of Occupational Health, N-0033 Oslo, Norway. petter.kristensen@stami.no

Refers to the following texts of the Journal: 2004;30(5):350-355 1999;25 suppl 2:1-116

Key terms: editorial; occupational epidemiology; randomization

This article in PubMed: www.ncbi.nlm.nih.gov/pubmed/15529796

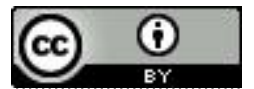




\section{Editorial}

Scand J Work Environ Health 2004;30(5):337-338

\section{Lack of randomization in occupational epidemiology}

In an ideal world, the effect of an occupational exposure would be measured by comparing the outcome in an exposed population for a specific time period with that in the same population during the same time period, but without exposure to the agent under study (1). This is, of course, counterfactual. Instead, we must deal with it differently. Randomization (ie, random assignment of subjects into exposure categories) is one way to approach the lack of comparability and uncontrolled confounding. Although potential confounding is not eliminated, we are able to account for its impact quantitatively. Randomized studies are seldom an option in occupational epidemiology. Assignment to occupational exposures in observational studies is typically the result of complex individual, group-dependent, and societal selection processes. We are used to approaching this problem by carefully selecting proper reference populations and by dealing with potential confounders in different stages of a study. Most of us are fully aware that we are not able to eliminate the problem in design and analysis, but we are used to dealing with it in the discussion part of a paper.

Lack of randomization came to mind when I read the article by Randem and her co-workers on cancer incidence among Nordic asphalt workers, published in this issue of the Scandinavian Journal of Work Environment \& Health (2). The paper is part of a large study, coordinated by the International Agency for Research on Cancer (3), in the European asphalt industry. This is a project of considerable quality. In an assessment, we should also recognize that Randem and her co-workers have overcome difficult challenges. The study involved workers employed by many different companies in four different countries. Furthermore, the study participants were partly seasonal workers, who are not easy to track and follow.

The study objective was to investigate cancer risk in relation to employment in the asphalt industry (2). A particular aim was to study low-mortality cancer sites, as a complement to the results of the European mortality study (3). In spite of the qualities of the study, the results are inconclusive. Many questions should therefore be asked, and few definite answers can be given. Can the small increase in lung cancer incidence be ascribed to occupational exposure, or is the result confounded by smoking? Is the bladder cancer result nonpositive or negative? Or do the subset analyses show that there is truly an occupational risk? We should also be aware that the authors' results, in some respects, are in contrast to the results of an earlier review and meta-analysis (4). In the meta-analysis (to a large extent based on studies from the United States) roofers had an increased risk for cancer of the lung and other sites, whereas road pavers had a relative risk close to unity for lung cancer (4). By contrast, Randem et al (2) found no increase in the standardized incidence ratio for roofers and a small increase for road pavers. Are these discrepancies due to different exposures or exposure levels, or are there other explanations?

The usual answer when such problems are encountered is to improve information quality on exposures and potential confounders (notably smoking). A nested case-referent study offers an opportunity for such improvement. But what about the lack of randomization in this study on standardized incidence ratios, in which study populations are compared with the general population in different countries?

The indirectly adjusted rate is the crude rate in the reference population multiplied by the exposure-specific standardized incidence ratio. Strictly speaking, comparisons of standardized incidence ratios are invalid unless all stratum-specific study population rates are a constant multiple of the 
specific reference population rates. It is well known that this assumption may be violated, being a source of (not too serious) bias (5). I suspect that the Nordic asphalt study could demonstrate another, and perhaps more serious, comparison problem. The country-specific all-cancer standardized incidence ratios in table 2 of the article (2) give an indication of this. The statement of Randem and her co-workers that there was a deficit in all the cancer incidences in all four countries (2) should be more specified. The standardized incidence ratios (SIR) did, in fact, differ between the two main person-time contributing countries, being close to unity (SIR 0.96, 95\% confidence interval 0.891.02) for Denmark and a deficit approximately six times larger for Norway (SIR $0.77,95 \%$ confidence interval 0.69-0.86). The results for Finland were close to the Norwegian ones, whereas the Swedish results were close to those of Denmark.

Asphalt workers in the Nordic countries are partly seasonal workers. The standardized incidence ratios for all cancers may indicate that there have been differences in recruitment to asphalt work across countries. What if workers in Finland and Norway were, to a large extent, recruited from farming, whereas workers in Denmark and Sweden were recruited from the general population or a pool of unemployed persons or maybe sailors? These suggested occupational groups are extremes concerning cancer incidence in the Nordic countries (SIR 79 for farmers, SIR 120 for seamen) (6). Standardized incidence ratios based on the general population as reference may therefore be difficult to interpret correctly in this particular study.

The solution would be to use internal comparison, as in a nested case-referent study. Randem et al point to the lack of individual information on off-season work and occupational history as a limitation of their study (2). I agree, but I also believe that the background information available should be broader and not restricted to occupational data alone. One indication is the increase in the standardized incidence ratio for stomach cancer (2), which may indicate that Danish workers were not comparable with the general population concerning socioeconomy and infection risk in childhood (7).

\section{References}

1. Greenland S, Rothman KJ. Measures of effects and measures of association. In: Rothman KJ, Greenland S, editors. Modern epidemiology. 2nd ed. Philadelphia (PA): Lippincott-Raven, 1997. p 59.

2. Randem BG, Burstyn I, Langård S, Svane O, Järvholm B, Kauppinen T, et al. Cancer incidence among Nordic asphalt workers. Scand J Work Environ Health 2004;30:350-355.

3. Bofetta P, Burstyn I. Studies of carcinogenicity of bitumen fume in humans. Am J Ind Med 2003;43:1-2.

4. Partanen T, Bofetta P. Cancer risk in asphalt workers and roofers: review and meta-analysis of epidemiologic studies. Am J Ind Med 1994;26:721-40.

5. Greenland S. Meta-analysis. In: Rothman KJ, Greenland S, editors. Modern epidemiology. 2nd ed. Philadelphia (PA): Lippincott-Raven, 1997. p 655.

6. Andersen A, Barlow L, Engeland A, Kjærheim K, Lynge E, Pukkala E. Work-related cancer in the Nordic countries. Scand J Work Environ Health 1999;25 Suppl 2:1-116.

7. Asghar RJ, Parsonnet J. Helicobacter pylori and risk for gastric adenocarcinoma. Semin Gastrointest Dis 2001;12: 203-8.

\author{
Petter Kristensen \\ National Institute of Occupational Health \\ N-0033 Oslo, Norway \\ petter.kristensen@stami.no
}

